\section{Expression of the HPV18/E6 oncoprotein induces DNA damage}

\author{
Elva I. Cortés Gutiérrez, ${ }^{1}$ \\ Catalina García-Vielma,, \\ Adriana Aguilar-Lemarroy, ${ }^{3}$ \\ Veronica Vallejo-Ruíz, ${ }^{4}$ \\ Patricia Piña-Sánchez, ${ }^{5}$ \\ Pablo Zapata-Benavides, ${ }^{2}$ \\ Jaime Gosálvez ${ }^{6}$
}

${ }^{1}$ Genetics Department, Centro de Investigación Biomédica del Noreste (CIBIN), Instituto Mexicano del Seguro Social (IMSS), Monterrey, Nuevo León, Mexico

${ }^{2}$ Doctoral Program, Faculty of Biology, Universidad Autónoma de Nuevo León, Nuevo, León, Mexico

${ }^{3}$ Immunology Division, Centro de Investigación Biomédica de Occidente (CIBO), Instituto Mexicano del Seguro Social (IMSS), Guadalajara, Jalisco, Mexico

${ }^{4}$ Centro de Investigación Biomédica de Oriente (CIBIOR), Instituto Mexicano del Seguro Social (IMSS), Metepec, Puebla, Mexico

${ }^{5}$ Laboratory of Molecular Oncology, Unidad de Investigación Médica en Enfermedades Oncológicas (UIMEO), Instituto Mexicano del Seguro Social (IMSS), Mexico City, Mexico ${ }^{6}$ Unit of Genetics, Department of Biology, Universidad Autónoma de Madrid, Spain

\footnotetext{
Abstract

This study investigated possible variations in DNA damage in $\mathrm{HeLa}$ cells with silenced expression of the HPV/E6 oncogene compared with HeLa cells with normal expression of the E6 oncogene using the DNA breakage detection-fluorescence in situ hybridization (DBD-FISH) technique and a whole human genome DNA probe. The variable levels of DNA breaks present were measured quantitatively using image analysis after whole-genome DNA hybridization. HeLa cells with silenced expression of the HPV18/E6 oncogene showed a significant decrease in DNA damage compared with parental cells with normal expression of the E6 oncogene. These results were confirmed by alkaline comet assay. In conclusion, we demonstrated a decrease in DNA damage in HeLa clones
}

associated with low expression of the HPV/E6 oncogene. The significance of this decrease regarding the HPV life cycle and carcinogenesis requires further exploration.

\section{Introduction}

High-risk (HR) types of the human papillomavirus (HPV) are causative agents in virtually all cases of cervical cancer as well as in a significant percentage of other anogenital and oropharyngeal cancers. ${ }^{1}$ The development of genomic instability is considered to be a key enabling hallmark in $\mathrm{HPV}$-induced carcinogenesis. HPV-associated carcinogenesis is an excellent model to study the development of chromosomal instability, because only two viral oncoproteins, E6 and E7, are consistently expressed in cervical carcinomas. ${ }^{2,3}$ The transforming properties of HR HPVs reside primarily in the $E 6$ and $E 7$ oncogenes, and the sustained expression of these genes appears to be essential for the maintenance of the transformed state of HPV-positive cells. ${ }^{4} E 6$ and E7 encode small proteins that play essential roles in the HPV life cycle. ${ }^{5-8}$ The ability of the HR HPV E6 and E7 proteins to promote the degradation of $\mathrm{p} 53$ and $\mathrm{pRb}$, respectively, has been suggested as a mechanism via which HPV oncogenes induce cellular transformation..$^{910}$ E6 and E7 also function to inactivate $\mathrm{p} 53$ and $\mathrm{pRb} .{ }^{11,12}$ These functions include association with additional cellular proteins, activation of telomerase, and immortalization of primary human keratinocytes. Although E6 and E7 or the HPV genome efficiently immortalize primary human epithelial cells, they are not sufficient to induce the transformation of human cells directly. ${ }^{13}$ It is believed that the genomic instability caused by E6 and E7 enables cells to accumulate additional genomic aberrations that are necessary to undergo malignant transformation.

Expression of E6 and E7 results in DNA damage and chromosomal aberrations. ${ }^{14}$ Multiple mechanisms have been proposed to explain these observations, such as replication stress and centrosome amplifications; ${ }^{15,16}$ however, the mechanisms underlying chromosomal instability and malignancy remain under investigation.

\section{DNA breakage detection-fluorescence in situ hybridization (DBD-FISH)}

This procedure allows the cell-by-cell detection and quantification of DNA breakage in the whole genome or within specific DNA sequences. Cells embedded in an inert agarose matrix on a slide are lysed to remove their membranes and proteins, and
Correspondence: Dr. Elva I. Cortés-Gutiérrez, Centro de Investigación Biomédica del Noreste, Instituto Mexicano del Seguro Social (IMSS), Monterrey, N.L. C.P. 64720, México. Tel./Fax: +52. 81.81904035.

E-mail: elvacortes@cibinmty.net

Key words: DNA damage; DNA breakage detection-fluorescence in situ hybridization; DBD-FISH; human papillomavirus; HPV; E6 oncogene; alkaline-labile sites.

Acknowledgments: we thank the International Cooperation Program of Instituto Mexicano del Seguro Social (IMSS), Mexico for the support received. GV-C is grateful for the scholarship obtained from CONACYT-México. P-PS is Research Fellow of Fundation IMSS

Funding: this study was supported by Fondo de Investigación en Salud-IMSS (FIS/ IMSS/PROT/MD13/1247 and Fondo Sectorial de Investigación en Salud y Seguridad Social SS/IMSS/ISSSTE-CONACYT (293539).

Received for publication: 17 January 2017. Accepted for publication: 30 April 2017.

This work is licensed under a Creative Commons Attribution-NonCommercial 4.0 International License (CC BY-NC 4.0).

(C) Copyright E.I. Cortés Gutiérrez et al., 2017 Licensee PAGEPress, Italy

European Journal of Histochemistry 2017; 61:2773 doi:10.4081/ejh.2017.2773

the remaining nucleoids are subjected to controlled denaturation using an alkali. The alkali transforms DNA breaks into restricted single-stranded DNA ( $s D N A)$ motifs, which can be detected by hybridization with specific or whole-genome fluorescent DNA probes. ${ }^{17}$ DBD-FISH performed using a whole-genome probe estimates the overall background damage in the genome. As the number of DNA breaks increases in a target region, more ssDNA is produced, and more probe hybridizes, resulting in a more intense FISH signal, which can be quantified with image analysis systems. ${ }^{18-20}$ Moreover, the alkaline treatment may break the sugar-phosphate backbone at abasic sites or at sites with deoxyribose damage, thus transforming these lesions into DNA breaks that are also converted into ssDNA.

DNA damage levels may be a consequence of the torsional stress on DNA loops associated with tight chromatin packing; it may vary between cell types in conventionally conformed genomes (for example, sperm and lymphocytes) ${ }^{21}$ and may change if the cell is under stress, such as in the case of gamma irradiation ${ }^{22}$ and HPV infection. ${ }^{23}$ 
The aim of this study was to evaluate DNA damage in parental HeLa cells with normal expression of the $E 6$ oncogene compared with $\mathrm{HeLa}$ clones with silenced expression of this oncogene using DBDFISH and the alkaline comet assay. This information will help to understand better the early steps of cancer development and may improve strategies to target chromosomal instability for preventive or therapeutic purposes.

\section{Materials and Methods}

\section{Cell culture}

HeLa cell lines derived from cervical cancer were donated generously by the German Cancer Research Center (DKFZ, Heidelberg, Germany). Cells were cultured in Dulbecco's modified Eagle's medium (DMEM) containing GlutaMAX ${ }^{\mathrm{TM}}$ and supplemented with $10 \%$ fetal bovine serum (FBS), $100 \mathrm{U} / \mathrm{mL}$ penicillin, and $100 \mu \mathrm{g} / \mathrm{ml}$ streptomycin at $37^{\circ} \mathrm{C}$ with an atmosphere of $5 \% \mathrm{CO}_{2}$ and $90 \%$ relative humidity $\left(\mathrm{GIBCO}^{\circledR}\right.$, Thermo Fisher Scientific, Inc., Waltham, MA, USA). Cells were propagated according to the methods recommended by the suppliers.

\section{Silencing of E6 from HPV18 in HeLa cells}

The silencing of HPV18/E6 was performed using the Lentiviral shRNA vector pLVX-shRNA1 (Cat. No. 632177, Clontech Laboratories, Inc., Mountain View, CA, USA). In that vector, the next sequences targeting HPV18-E6 were inserted between the BamHI and EcoRI clone sites: Forward 5 ' - g a t c c G C T A A C A C T G G G T T A TACAATTCAAGAGATTGTATAACCCA GTGTTAGTTTTTTg-3', Reverse 5'aattcAAAAAACTAACACTGGGTTATAC AATCTCTTGAATTGT ATAA CCCAGTGTT AGCg-3'. These sequences include the BamHI and EcoRI restriction sites for an easier cloning. Production of viral particles was performed in the Lenti-X 293T cells transient- transfected with the Lentiphos $^{\mathrm{TM}}$ HT protocol using the Lenti-X HT packaging system (Cat. No. 632160, Clontech Laboratories) as recommended by the manufacturers. Subsequently, HeLa cells were transduced with the viral particles by incubated them for $72 \mathrm{~h}$ and clonal selection was performed by selection with puromycin.

\section{Real Time PCR}

For RNA analysis, total RNA was isolated using the PureLink ${ }^{\mathrm{TM}}$ Micro-to-Midi
Total RNA Purification System, follow by cDNA synthesis using the SuperScript ${ }^{\mathrm{TM}}$ III First-Strand Synthesis System for RT-PCR (both kits from Life Technologies Corporation, Carlsbad, CA, USA). Realtime PCR was carried out in a LightCycler 2.0 device using the LightCycler FastStart DNA Master SYBR Green I kit (Roche Applied Science, Penzberg, Germany). Ribosomal Protein S18 (RPS18) and Ribosomal Protein L32 (RPL32) were used as reference genes to determine relative expression of the target genes. The following primers were used:

HPV18-E6: Forward (GCGACCCTACAAGCTACCTGAT); HPV18-E6 Reverse (GCACCGCAGGCA CCTTATTA);

RPS18: Forward (CGATGGGCGG CGG AAAA); RPS18 (Reverse CAGTCGCTC CAGGTCTTCA CGG);

RPL32: Forward (GCATTGACAACAGG GTTCGTAG); RPL32 Reverse (ATTTAAACAGAAAACG TG CACA).

\section{DBD-FISH}

DBD-FISH involves a protein depletion procedure followed by treatment with an alkaline solution, to produce ssDNA. ${ }^{24}$ To deplete the proteins in epithelial cells, the slides were treated with a solution of $2 \mathrm{M}$ $\mathrm{NaCl}, 0.05 \mathrm{M}$ EDTA, 0.4 M Tris-base, and $1 \% \operatorname{SDS}(\mathrm{pH} 7)$ at $43^{\circ} \mathrm{C}$ for $25 \mathrm{~min}$. The slides were incubated horizontally, to avoid chromatin dispersion.

After the initial protein removal, the remaining nucleoids were washed in $0.9 \%$ $\mathrm{NaCl}$ for $10 \mathrm{~min}$, to facilitate the final protein removal. To generate ssDNA, the protein-depleted slides were incubated in an alkaline unwinding solution containing 0.03 $\mathrm{M} \mathrm{NaOH}$ and $1 \mathrm{M} \mathrm{NaCl}$ (pH 12.5) for 2.5 min at room temperature. After the sample was neutralized with $0.4 \mathrm{M}$ Tris- $\mathrm{HCl}(\mathrm{pH}$ 7.5 ) for $5 \mathrm{~min}$, the nucleoids were washed in TBE buffer ( $89 \mathrm{mM}$ Tris, $89 \mathrm{mM}$ boric acid, 2.5 mM EDTA, pH 8.3) for $2 \mathrm{~min}$. To stabilize the ssDNA, the slides were dehydrated in sequential $70 \%, 90 \%$, and $100 \%$ ethanol baths for 2 min each, and then air-dried.

A whole-genome DNA probe was produced from lymphocyte pellets using a DNA isolation kit for mammalian blood (Roche Diagnostics Corporation, Indianapolis, IN, USA). An aliquot $(1 \mu \mathrm{g})$ of each DNA sample was labeled with biotin-14-2'-deoxyuridine 5'-triphosphate (dUTP), using a commercial nick-translation kit (Roche Diagnostics Corporation). The whole-genome probe labeled with biotin was denatured and incubated overnight on the dried gels at room temperature. The slides were then washed twice at room temperature with $50 \%$ formamide,
$2 \times \mathrm{SSC}(\mathrm{pH} 7)$ for $5 \mathrm{~min}$, and then in $2 \times$ $\mathrm{SSC}(\mathrm{pH} 7$ ) for $3 \mathrm{~min}$. The hybridized DNA probe was detected by incubation for 30 min with FITC-labeled avidin (1:400; Roche Diagnostics Corporation). Finally, the slides were counterstained with $4^{\prime}, 6-$ diamidino-2-phenylindole (DAPI) $(1 \mu \mathrm{g} / \mathrm{mL})$ in Vectashield mounting medium (Vector Laboratories, Burlingame, CA, USA). Cells with much higher area of labeling associated to DNA replication (cells in phase-S), and apoptotic cells were excluded of analysis. $^{20}$

Slides were analyzed on a digital image analysis platform based on a Zeiss Axiophot (Carl Zeiss, Göttingen, Germany) fluorescence microscope equipped with three lowpass band filters to visualize green, red, and blue fluorescent emissions. The images were recorded using an Axiocam 16-bit black-and-white CCD camera in a 12-bit TIFF format. The integrated density (ID; segmented area of interest $\times$ gray-level values obtained after background subtraction) was calculated using the ImageJ 1.4.3.6.7 analysis software (National Institutes of Health, Bethesda, MD, USA, 2012). Fifty nuclei were examined for each experiment.

\section{Comet assay}

To confirm the results obtained with DBD-FISH, the alkaline comet assay was performed as described by Singh et al. ${ }^{25}$ The protein depletion, alkaline unwinding, and alkaline treatments were performed as described previously for the DBD-FISH technique. The slides were placed horizontally on an electrophoresis tray, which was filled with fresh alkaline electrophoresis solution (0.03 M NaOH, pH 13). Electrophoresis was then conducted on ice using an electric field of $25 \mathrm{~V}$ for $20 \mathrm{~min}$. All of these steps were carried out in a dark room, to prevent interference by additional DNA damage. After electrophoresis, the slides were gently removed from the tray and washed with neutralizing buffer for 5 min. The slides were washed in distilled $\mathrm{H}_{2} \mathrm{O}$ for $5 \mathrm{~min}$ and then dehydrated in a sequential series of $70 \%, 90 \%$, and $100 \%$ ethanol baths ( 2 min each) and were then air-dried. Finally, the slides were stained with propidium iodide $(1 \mu \mathrm{g} / \mathrm{mL})$ in Vectashield (Vector Laboratories). Cells treated with $\mathrm{H}_{2} \mathrm{O}_{2}$ at $20 \mu \mathrm{M}$ were including as a positive control.

All experiments were performed in duplicate and repeated independently at least twice.

One hundred cells for experiment were scored for the distribution of DNA between the 'tail' and the 'head'; the DNA that remained in the nucleus (head) represents 
undamaged DNA, whereas the tail contains fragmented DNA that was able to move out of the cell body during electrophoresis.

\section{Statistical analysis}

The Mann-Whitney nonparametric Utest was used for evaluating differences in fluorescence (area, intensity, and ID) between parental HeLa cells with normal expression of the E6 oncogene and HeLa clones with silenced expression of this oncogene after DBD-FISH. For the comet assay, variance test with one criterion (oneway ANOVA) was performed. $\mathrm{P}<0.05$ was considered significant. All analyses were performed using IBM SPSS for Windows 20.0 (IBM Corp., Armonk, NY, USA).

\section{Results}

\section{E6 expression in HeLa cells}

To confirm E6 expression silencing, real time PCR was performed utilizing E6 specific primers. E7 expression was also measured, since it is known that both genes expressed from a bicistronic mRNA. As depicted in Figure 1, E6 expression in the HeLa-shE6 reduces significantly when normalized with RPS18 or RPL32 genes setting HeLa parental cells as calibrator (set as 1). A decreased expression of E7 was also observed.

\section{DNA damage after of silencing HPV18/E6 in HeLa cells}

DBD-FISH performed under mild alkaline denaturing conditions for protein removal and DNA production led to the detection of DNA breaks. The DNA damage observed in parental cells was considered as the normal-level or constitutive damage for HeLa cells (Figure 1B). In contrast, a significant decrease in DNA damage was observed in cells with silenced expression of the HPV18/E6 oncogene (Figure 2A, Table 1). As a control treatment, $\mathrm{H}_{2} \mathrm{O}_{2}$ produced pronounced DNA damage, which confirmed the accessibility of the cells to the test chemicals and the efficient functionality of the technique (Figure 2C).

The presence of DNA breaks detected by DBD-FISH was confirmed using a comet assay performed under alkaline conditions (Figure 2). The comet assay revealed that all cells showed the presence of a 'comet tail' of denatured DNA. The length of the tails (in $\mu$ m; mean \pm standard deviation) obtained for parental HeLa cells with normal expression of the $E 6$ oncogene (126 \pm 7.83 ) (Figure 2B') was significantly greater $(\mathrm{P}<0.01)$ than that observed for cells with silenced expression of this oncogene (58.76 \pm 8.52 ; Figure 2A'). Positive control showed higher values of DNA damage (271.76 \pm 10.16 ); Figure 2C').

\section{Discussion}

Cervical cancer is characterized as being a 'disease of chromosomal instability' because the viral oncoproteins E6 and E7 are consistently expressed in these tumors. ${ }^{26}$ This damage to DNA may lead to the mutations, aberrations, and chromosomal

Table 1. Fluorescence analysis of parental HeLa cells and clones with silenced expression of the HPV18/EG oncogene after DBD-FISH.

\begin{tabular}{lccc} 
HeLa cells & Area $(\mathrm{X} \pm$ SD) & $\begin{array}{c}\text { Fluorescence analysis } \\
\text { intensity }(\mathrm{XD})\end{array}$ & Integrity density $(\mathrm{X} \pm \mathrm{SD})$ \\
Parental & $56.52 \pm 40.37^{* \circ}$ & $138.83 \pm 39.78^{* \circ}$ & $7846.67 \pm 7327.08^{* \circ}$ \\
E6 silenced & $11.93 \pm 13.31^{\sharp \circ}$ & $243.47 \pm 6.10^{\sharp \circ}$ & $2904.60 \pm 3246.86^{\sharp \circ}$ \\
\hline Positive control & $175.21 \pm 68.32^{\# *}$ & $471.92 \pm 84.64^{\# *}$ & $82685.10 \pm 115683^{* *}$ \\
\hline
\end{tabular}

*Different to E6 silenced; ${ }^{\circ}$ different to positive control; ${ }^{\sharp}$ different to parental.

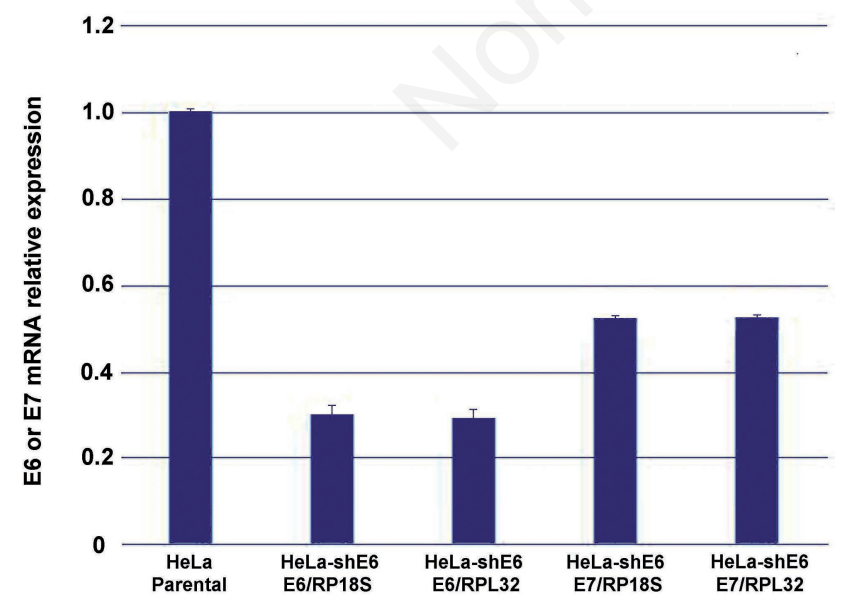

Figure 1. Relative expression of HPV18/EG oncogene in parental HeLa cells, silenced E6 (HeLa-shE6), and E7 (HeLa-shE7). The graphs show the mean \pm the standard deviation using two different constituent genes for normalization (RPS18), and RPL32). The value of the parent HeLa cells was used as the calibrator.
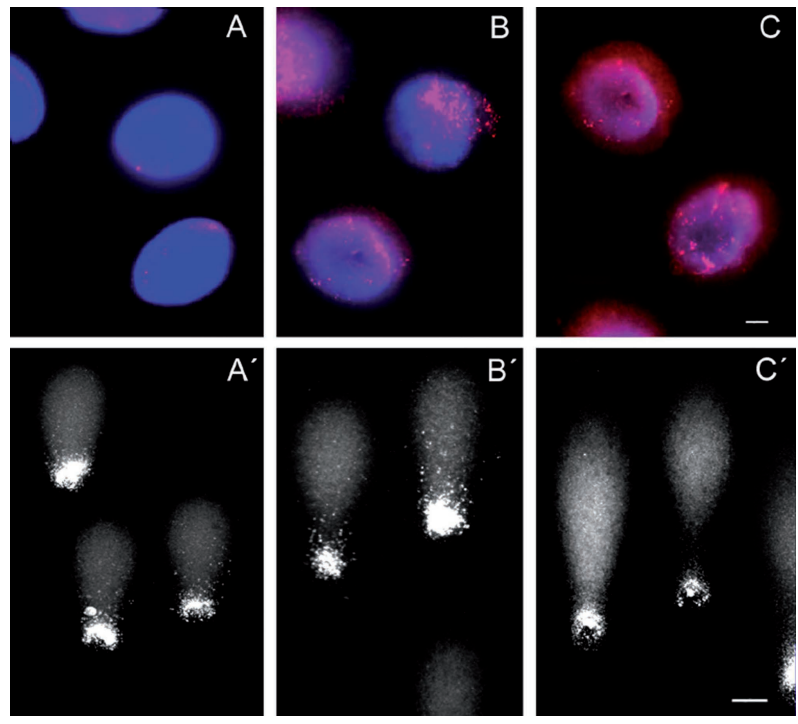

Figure 2. DBD-FISH in parental HeLa cells (B), in cells with silenced expression of the HPV18/EG oncogene (A), and in a positive control treated with $0.01 \% \mathrm{H}_{2} \mathrm{O}_{2}(\mathrm{C})$. Confirmation of DNA breaks by the alkaline comet assay $\left(\mathrm{A}^{\prime}-\mathrm{C}^{\prime}\right)$, respectively. Scale bars: A-C) $5 \mu \mathrm{m} ; A^{\prime}-C^{\prime}$ ) $10 \mu \mathrm{m}$. 
rearrangements associated with HPV infection and cell transformation. ${ }^{27,28} \mathrm{~A}$ sufficient number of events may ultimately allow the occurrence of numerical and/or structural genetic alterations that confer a growth advantage and facilitate traversing selection barriers. ${ }^{29}$ However, the pathogenesis of complex chromosomal changes is unclear.

We demonstrated a decrease in DNA damage in HeLa cells associated with a low expression of the HPV18/E6 oncogene, as detected by DBD-FISH and alkaline comet assay. These data are in accordance with previous studies that showed an association between the expression of HPV oncogenes and chromosomal instability.

The majority of HR HPV-associated lesions become numerical chromosomal aberrations, such as polyploidy and aneusomias. ${ }^{30-33}$ In addition, complex cytogenetic aberrations with chromosomal gains or losses, as well as deletions or amplifications of chromosome arms, are detected in HPV immortalized cells ${ }^{34}$ and cervical cancers. ${ }^{28,35}$

Previously, it was thought, but not shown directly, that the HR E6 protein induces polyploidy in response to microtubule disruption by abrogating the spindle checkpoint, and that E6 promotes the degradation of the tumor suppressor p53. ${ }^{36}$ Unaligned or lagging chromosomal material during cell division can result in defects of the mitotic spindle checkpoint. This checkpoint normally monitors the proper attachment of kinetochores to spindle microtubules and the alignment of all chromosomes at the metaphase plate. ${ }^{37}$ It was shown previously that the HPV-16 E6 and E7 oncoproteins abrogate mitotic checkpoint control. ${ }^{38,39}$

A mechanism via which E6 and E7 induce polyploidy upon DNA damage was proposed, but not directly demonstrated, involving cytokinesis failure as a result of p53 inactivation and poly-like kinase 1 (Plk1) upregulation. ${ }^{40}$ pRB plays a role in cell-cycle arrest after DNA damage ${ }^{41}$ and inactivation of $\mathrm{pRB}$ itself has been implicated in genomic instability. ${ }^{42}$ This finding is supported by previous observations that the HR HPV E7 protein enhances the integration of DNA into chromosomes. ${ }^{43}$ Direct interaction between a viral oncoprotein and a mitotic spindle checkpoint protein has been described for the HTLV-1 oncoprotein Tax, ${ }^{44}$ but no similar interactions have been reported for HPV E6 or E7.

A previous study showed that centrosome-related mitotic disturbances are a prominent finding in HPV oncoproteinexpressing cells, and that these abnormalities are caused by expression of HR HPV
E6 and E7. Interestingly, cells with HPV-16 episomes in which the E7 oncoprotein was inactivated showed a significant reduction of basal cells with centrosome abnormalities. $^{45}$

A previous study reported anaphase bridges and micronuclei as nuclear abnormalities that correlate with structural chromosomal changes in HPV-16 E6/E7expressing cells. Anaphase bridges have been observed in various malignancies and are believed to result from chromosomal breaks and formation of di- or multicentromeric chromosomes, thus hindering proper segregation during mitosis. If anaphase bridges break, chromosome fragments that are able to fuse with other chromosomes can be generated, and repeated cycles of breakage-bridge-fusion can occur. ${ }^{46,47}$ Cells with extra centrosomes in mitosis may form multipolar spindles (also called 'multipolar mitosis' or "multipolar metaphase"). The spontaneous occurrence of multipolar metaphases and a decrease in the levels of p53 were observed in HPV E6 mutant-expressing cells. ${ }^{48}$ By using the Comet assay, two independent groups have previously reported that expression of HPV16- E6 increase oxidative stress and thus the amount of DNA damage. Williams et $a l .{ }^{49}$ demonstrated that expression of the HPV16 E6* isoform increases oxidative stress and induces oxidative DNA damage in cell culture derived from human cervical carcinomas (CaSki and $\mathrm{SiHa}$ ), mouse fibrosarcoma cells (L9299, and human osteosarcoma (U2OS). Marullo et al..$^{50}$ reported than HPV16 E6 and E7 proteins induce a chronic oxidative stress response via NOX2 that causes genomic instability and increased susceptibility to DNA damage in head and neck cancer cells. It has been suggested that micronuclei may originate from acentric chromosome fragments, either resulting from double-strand DNA damage before cell division or after the breakage of anaphase bridges ${ }^{47}$ In our previous study, we demonstrated an increase of $\mathrm{MN}$ in patients with cervical neoplasia and HPV-HR infection. ${ }^{51}$ The link between chromosomal instability and telomere erosion has been well established. ${ }^{52}$ A clear correlation between telomerase activity and chromosomal rearrangements is found in HPV-16 E6/E7-expressing cells.

In p53 mutant mice lacking the telomerase RNA component (mTerc), a strong correlation was found between telomere erosion and numerous complex unbalanced translocations, ${ }^{53}$ as well as the number of anaphase bridges. ${ }^{54} \mathrm{~A}$ correlation between chromosomal instability and telomere erosion was demonstrated in human fibroblasts expressing $H P V-16 E 6 .{ }^{55}$

In addition to previous biomarkers that were used for the evaluation of DNA damage, the DBD-FISH technique is a biomarker that deserves special attention because of its high sensitivity. ${ }^{17}$ The present study was performed by analyzing the overall genome using a whole-genome probe. However, many different specific probes could be hybridized, with the possibility of analyzing chromosomal instability in HPV-HR oncogene-expressing cells within specific DNA sequence areas. ${ }^{24}$

In conclusion, we demonstrated a decrease in DNA damage in HeLa clones associated with a low expression of the HPV E6 oncogene. The significance of this decrease for the HPV life cycle and carcinogenesis requires further exploration. From a clinical perspective, our findings provide a better understanding of the early steps of cancer development and may improve strategies to target chromosomal instability for preventive or therapeutic purposes.

\section{References}

1. Burd EM. Human papillomavirus and cervical cancer. Clin Microbiol Rev 2003;16:1-17.

2. zur Hausen H. Viruses in human cancers. Science1991;254:1167-73.

3. Howley PM, Lowy DR. Papillomaviruses and their replication. In: D.M. Knipe and P.M. Howley (eds.), Field's virology, Vol. 2, Philadelphia: Lippincott Williams \& Wilkins, 2001; pp. 2197-229.

4. Alvarez-Salas LM, Cullinan AE, Siwkowski A, Hampel A, DiPaolo JA. Inhibition of HPV-16 E6/E7 immortalization of normal keratinocytes by hairpin ribozymes. Proc Natl Acad Sci USA1998;95:1189-14.

5. Thomas JT, Hubert WG, Ruesch MN, Laimins LA. Human papillomavirus type 31 oncoproteins E6 and E7 are required for the maintenance of episomes during the viral life cycle in normal human keratinocytes. Proc Natl Acad Sci USA 1999;96:8449-54.

6. Flores ER, Allen-Hoffmann BL, Lee D, Lambert PF. The human papillomavirus type $16 \mathrm{E} 7$ oncogene is required for the productive stage of the viral life cycle. J Virol 2000;74:6622-31.

7. Oh ST, Longworth MS, Laimins LA. Roles of the E6 and E7 proteins in the life cycle of low-risk human papillomavirus type 11. J Virol 2004;78:2620-6. 8. McLaughlin-Drubin ME, Bromberg- 
White JL, Meyers C. The role of the human papillomavirus type $18 \mathrm{E} 7$ oncoprotein during the complete viral life cycle. Virology 2005;338:61-8.

9. Scheffner M, Huibregtse JM, Vierstra RD, Howley PM. The HPV-16 E6 and E6-AP complex functions as a ubiquitin-protein ligase in the ubiquitination of p53. Cell 1993;75:495-505.

10. Dyson N, Howley PM, Munger K, Harlow E. The human papilloma virus$16 \mathrm{E} 7$ oncoprotein is able to bind to the retinoblastoma gene product. Science 1989;243:934-7.

11. Fan X, Chen JJ. Regulation of cell cycle progression and apoptosis by the papillomavirus E6 oncogene. Crit Rev Eukaryot Gene Expr 2004;14:183-202.

12. Münger K, Basile JR, Duensing S, Eichten A, Gonzalez SL, Grace M, et al. Biological activities and molecular targets of the human papillomavirus E7 oncoprotein. Oncogene 2001;20:788898.

13. Munger K, Howley PM. Human papillomavirus immortalization and transformation functions. Virus Res 2002;89: 213-28.

14. Duensing S, Munger K. The human papillomavirus type $16 \mathrm{E} 6$ and $\mathrm{E} 7$ oncoproteins independently induce numerical and structural chromosome instability. Cancer Res 2002;62:7075-82.

15. Bester AC, Roniger M, Oren YS, Im MM, Sarni D, Chaoat M, et al. Nucleotide deficiency promotes genomic instability in early stages of cancer development. Cell 2011;145: 435-46.

16. Duensing S, Duensing A, Crum CP, Münger K. Human papillomavirus type 16 E7 oncoprotein-induced abnormal centrosome synthesis is an early event in the evolving malignant phenotype. Cancer Res 2001;61:2356-60.

17. Fernández JL, Vázquez-Gundín F, Delgado A, Goyanes VJ, Ramiro-Díaz $\mathrm{J}$, de la Torre J, et al. DNA breakage detection-FISH (DBD-FISH) in human spermatozoa: technical variants evidence different structural features. Mutat Res 2000;453:77-82.

18. Cortés-Gutiérrez EI, Ortíz-Hernández BL, Dávila-Rodríguez MI, CerdaFlores RM, Fernández JL, LópezFernández C, et al. 5-bp classical satellite DNA loci from chromosome-1 instability in cervical neoplasia detected by DNA breakage detection/fluorescence in situ hybridization (DBD-FISH) Int J Mol Sci 2013;14:4135-47.

19. Cortés-Gutiérrez EI, Dávila-Rodríguez MI, Fernández JL, López-Fernández C,
Gosálvez J. DNA breakage detectionfluorescence in situ hybridization in buccal cells. Eur J Histochem 2012; 56:e49.

20. Fernández JL, Gosálvez J. Application of FISH to detect DNA damage. DNA breakage detection-FISH (DBD-FISH). Methods Mol Biol 2002;203:203-16.

21. Cortés-Gutiérrez EI, Dávila-Rodríguez MI, López-Fernández C, Fernández JL, Gosálvez J. Alkali-labile sites in sperm cells from Sus and Ovis species. Int J Androl 2008;31:354-63.

22. Fernández JL, Vazquez-Gundin F, Rivero MT, Goyanes V, Gosálvez J. Evidence of abundant constitutive alkali-labile sites in human 5 bp classical satellite DNA loci by DBD-FISH. Mutation Res 2001;473:163-8.

23. Cortés-Gutiérrez EI, Dávila-Rodríguez MI, Fernández JL, López-Fernández C, Gosálvez J. Koilocytes are enriched for alkaline-labile sites. Eur J Histochem 2010;54:e32.

24. Fernández JL, Vázquez-Gundín F, Rivero MT, Goyanes V, Gosálvez J. Evidence of abundant constitutive alkali-labile sites in human 5 bp classical satellite DNA loci by DBD-FISH. Mutat Res 2001;473:163-8.

25. Singh NP, McCoy MT, Tice RR, Schneider EL. A simple technique for quantitation of low levels of DNA damage in individual cells. Exp Cell Res 1988;175:184-91.

26. Klausner RD. The fabric of cancer cell biology: weaving together the strands. Cancer Cell 2002;1:3-10.

27. Lengauer C, Kinzler KW, Vogelstein B. Genetic instabilities in human cancers. Nature 1998;396:643-9.

28. Heselmeyer K, Schrock E, du Manoir S, Blegen H, Shah K, Steinbeck R, et al. Gain of chromosome $3 q$ defines the transition from severe dysplasia to invasive carcinoma of the uterine cervix. Proc Natl Acad Sci USA 1996;93:479-84.

29. Cahill DP, Kinzler KW, Vogelstein B, Lengauer C. Genetic instability and darwinian selection in tumours. Trends Cell Biol 1999;9:M57-60.

30. Bibbo M, Dytch HE, Alenghat E, Bartels PH, Wied GL. DNA ploidy profiles as prognostic indicators in CIN lesions. Am J Clin Pathol 1989;92:261-5.

31. Fu YS, Reagan JW, Richart RM. Definition of precursors. Gynecol Oncol 1981;12:S220-31.

32. Reid R, Crum CP, Herschman BR, Fu YS, Braun L, Shah KV, et al. Genital warts and cervical cancer. III. Subclinical papillomaviral infection and cervical neoplasia are linked by a spectrum of continuous morphologic and biologic changes. Cancer 1984;53: 943-53.

33. Southern SA, Evans MF, Herrington CS. Basal cell tetrasomy in low-grade cervical squamous intraepithelial lesions infected with high-risk human papillomaviruses. Cancer Res 1997;57: 4210-3.

34. Solinas-Toldo S, Dürst M, Lichter P. Specific chromosomal imbalances in human papillomavirus-transfected cells during progression toward immortality. Proc Natl Acad Sci USA 1997;94:3854-9.

35. Heselmeyer K, Macville M, Schrock E, Blegen H, Hellström AC, Shah K, et al. Advanced-stage cervical carcinomas are defined by a recurrent pattern of chromosomal aberrations revealing high genetic instability and a consistent gain of chromosome arm 3q. Genes Chromosomes Cancer 1997;19:233-40.

36. Patel D, Incassati A, Wang N, McCance DJ. Human papillomavirus type 16 E6 and E7 cause polyploidy in human keratinocytes and up-regulation of G2-Mphase proteins. Cancer Res 2004;64: 1299-306.

37. Amon A. The spindle checkpoint. Curr Opin Genet Dev 1999;9:69-75.

38. Thompson DA, Belinsky G, Chang TH, Jones DL, Schlegel R, Munger K. The human papillomavirus-16 E6 oncoprotein decreases the vigilance of mitotic checkpoints. Oncogene 1997;15:3025-35.

39. Thomas JT, Laimins LA. Human papillomavirus oncoproteins E6 and E7 independently abrogate the mitotic spindle checkpoint. J. Virol 1998;72:1131-7.

40. Incassati A, Patel D, McCance DJ. Induction of tetraploidy through loss of p53 and upregulation of Plk1 by human papillomavirus type-16 E6. Oncogene 2005;25:2444-51.

41. Oh ST, Longworth MS, Laimins LA. Roles of the E6 and E7 proteins in the life cycle of low-risk human papillomavirus type 11. J Virol 2004;78:2620-6.

42. McLaughlin-Drubin ME, BrombergWhite JL, Meyers C. The role of the human papillomavirus type 18 E7 oncoprotein during the complete viral life cycle. Virology 2005;338:61-8.

43. Kessis TD, Connolly DC, Hedrick L, Cho KR. Expression of HPV16 E6 or E7 increases integration of foreign DNA. Oncogene 1996;13:427-31.

44. Jin DY, Spencer F, Jeang KT. Human T cell leukemia virus type 1 oncoprotein Tax targets the human mitotic checkpoint protein MAD1. Cell 1998;93:81-91.

45. Duensing S, Münger K. Human papillomaviruses and centrosome duplication 
errors: modeling the origins of genomic instability. Oncogene 2002;21:6241-8.

46. Gisselsson D, Pettersson L, Hoglund M, Heidenblad M, Gorunova L, Wiegant J, et al. Chromosomal breakage fusionbridge events cause genetic intratumor heterogeneity. Proc Natl Acad Sci USA 2002;97:5357-62.

47. McClintock B. The stability of broken ends of chromosomes in Zea mays. Genetics 1940;26:234-82.

48. Plug-Demaggio AW, McDougall JK. The human papillomavirus type 16 E6 oncogene induces premature mitotic chromosome segregation. Oncogene 2002;21:7507-13.

49. Williams VM, Filippova M, Filippov V, Payne KP, Duerksen-Hughesa P. Human papillomavirus Type 16 E6* induces oxidative stress and DNA damage. J Virol 2014;88: 6751-61.

50. Marullo R, Werner E, Zhang H, Chen GZ, Shin DM, Doetsch PW. HPV16 E6 and $\mathrm{E} 7$ proteins induce a chronic oxidative stress response via NOX2 that causes genomic instability and increased susceptibility to DNA damage in head and neck cancer cells. Carcinogenesis 2015;36:1397-406.

51. Cortés-Gutiérrez EI, Dávila-Rodríguez MI, Vargas-Villarreal J, HernándezGarza F, Cerda-Flores RM. Association between human papilloma virus-type infections with micronuclei frequencies. Prague Med Rep 2010;111:35-41.

52. Maser RS, DePinhO RA. Keeping telomerase in its place. Nat Med 2002;8:934-6.
53. Artandi SE, Chang S, Lee SL, Alson S, Gottlieb GJ, Chin L, et al. Telomere dysfunction promotes non-reciprocal translocations and epithelial cancers in mice. Nature 2000;10:641-5.

54. Rudolph KL, Millard M, Bosenberg MW, DePinho RA. Telomere dysfunction and evolution of intestinal carcino$\mathrm{ma}$ in mice and humans. Nat Genet 2001;28:155-9.

55. Filatov L, Golubovskaya V, Hurt JC, Byrd LL, Phillips JM, Kaufmann WK. Chromosomal instability is correlated with telomere erosion and inactivation of G2 checkpoint function in human fibroblasts expressing human papillomavirus type 16 E6 oncoprotein. Oncogene 1998;16:1825-38. 